\title{
Mechanical and Microstructural Response of Aluminum Composites Reinforced with Ceramic Micro-Particles
}

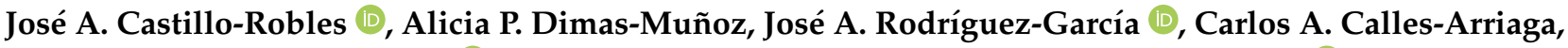 \\ Eddie N. Armendáriz-Mireles $\mathbb{B}$, Wilian J. Pech-Rodríguez and Enrique Rocha-Rangel * ${ }^{\mathbb{C}}$
}

Research Department, Universidad Politécnica de Victoria, Ciudad Victoria 87138, Tamaulipas, Mexico; jcastillor@upv.edu.mx (J.A.C.-R.); 1439002@upv.edu.mx (A.P.D.-M.); jrodriguezg@upv.edu.mx (J.A.R.-G.); ccallesa@upv.edu.mx (C.A.C.-A.); earmendarizm@upv.edu.mx (E.N.A.-M.); wpechr@upv.edu.mx (W.J.P.-R.)

* Correspondence: erochar@upv.edu.mx; Tel.: +52-834-100-171-11-00

Citation: Castillo-Robles, J.A.;

Dimas-Muñoz, A.P.;

Rodríguez-García, J.A.;

Calles-Arriaga, C.A.;

Armendáriz-Mireles, E.N.;

Pech-Rodríguez, W.J.;

Rocha-Rangel, E. Mechanical and

Microstructural Response of

Aluminum Composites Reinforced with Ceramic Micro-Particles. J.

Compos. Sci. 2021, 5, 228.

https://doi.org/10.3390/jcs5090228

Academic Editor: Konda

Gokuldoss Prashanth

Received: 2 August 2021

Accepted: 16 August 2021

Published: 27 August 2021

Publisher's Note: MDPI stays neutral with regard to jurisdictional claims in published maps and institutional affiliations.

Copyright: (c) 2021 by the authors. Licensee MDPI, Basel, Switzerland. This article is an open access article distributed under the terms and conditions of the Creative Commons Attribution (CC BY) license (https:/ / creativecommons.org/licenses/by/ $4.0 /)$.

\begin{abstract}
Aluminum matrix composites have recently taken an important role in advanced applications because they have a good combination of physical and chemical properties. For this reason, in this work, aluminum composites, with additions of ceramic particles (mullite or tungsten carbide), were manufactured in order to determine the effect of those particles on the mechanical properties and microstructure of aluminum. The manufacture of the composites was carried out by means of powder metallurgy. We studied composites with additions of 0.5 and $1 \mathrm{vol} . \%$ of the respective ceramic. Composites were sintered at 580 and $601{ }^{\circ} \mathrm{C}$, which corresponds to 88 and $91 \%$ of the melting point of aluminum, respectively. Observations in SEM, together with EDX analysis, confirm that mullite particles are located at intragranular and transgranular positions of the aluminum matrix, while tungsten carbide particles were found mostly at intragranular areas of the matrix. From the analysis of the studied ceramics, it was found that with the use of mullite, there are greater improvements in the hardness and elastic modulus of the manufactured composite.
\end{abstract}

Keywords: aluminum matrix; powder metallurgy; mechanical properties

\section{Introduction}

The use of aluminum matrix composites (AMC's) with unique properties is growing day by day in different industries, due to their high resistance-weight ratio, good corrosion resistance, and high thermal and electrical conductivity [1-3]. These composites initially substituted some cast iron and bronze alloys, but owing to their poor wear resistance, they were subjected to many experiments in order to understand their wear behavior. The results of these experiments have been reported by several researchers during the last three decades [4-6]. Scientists have found that the incorporation of different types of reinforcement materials, such as ceramics, metals, and intermetallic particles, have proved to be an effective way to increase the wear properties of the aluminum matrix. This is how AMC's have been manufactured with the addition of different compounds that are intended to be the reinforcers of the metallic matrix, thus the AMC's have been manufactured with $\mathrm{SiC} / \mathrm{B}_{4} \mathrm{C}$ [7], $\mathrm{SiC} / \mathrm{Al}_{2} \mathrm{O}_{3}$ [8], $\mathrm{TiC}$ [9], alloys of $\mathrm{Fe}-\mathrm{Cr}-\mathrm{Al} / \mathrm{Y}_{2} \mathrm{O}_{3}$ [10], $\mathrm{FeC} / \mathrm{Cr}_{2} \mathrm{C}$ [11]. Likewise, they have been processed through very different methods, such as stir casting [12], powder metallurgy [13], spray atomization and co-deposition [14], plasma spraying [15], and squeeze-casting [16]. These composites have been manufactured to produce lightweight components with high, specific mechanical properties such as wear resistance, thus they have been applied in the automotive and aeronautical industry where the reduction of weight, wear, friction, and low coefficient of thermal expansion are important [1]. A situation to consider is that, to date, the production of the $\mathrm{AMC}^{\prime} \mathrm{s}$ has been conducted through very sophisticated methods, using a special aluminum alloy $[8,10,11]$ or using very special reinforcing materials, such as graphene [17-19]. Depending on the route of processing and according to the findings in the literature, the incorporation of 
non-metallic ceramic reinforcements in aluminum increase the mechanical properties of AMC's, resulting advantages such as: hardness, strength, fatigue, fracture, degradation, and corrosion resistance, due to the small grain size and homogeneity of their microstructures [20]. This work aims to study the effect of small volume fraction additions of tungsten carbide or mullite on the mechanical properties of pure aluminum, processed by powder metallurgy techniques, which represents a combination of conditions not studied so far.

\section{Materials and Methods}

The AMC's were prepared using the following precursor powders: Aluminum $(99.9 \%$, $1 \mu \mathrm{m}$, Sigma-Aldrich, St. Louis, MO, USA), Mullite- $3 \mathrm{Al}_{2} \mathrm{O}_{3} \cdot 2 \mathrm{SiO}_{2}(99.9 \%,<10 \mu \mathrm{m}$, SigmaAldrich) and Tungsten Carbide-WC $(99.9 \%,<100 \mathrm{~nm}$, Sigma-Aldrich). The amounts of the ceramic added were $0,0.5$, and 1 vol. $\%$, whereas the batch of each studied system was $25 \mathrm{~g}$. The powders were mixed and grounded in a planetary type of mill (Retsch, PM100, NJ, USA), using $\mathrm{ZrO}_{2}$ balls of $3 \mathrm{~mm}$ diameter as the grinding medium, in a ratio of 11:1 ball weight:weight of the powder, grinding was done at $300 \mathrm{rpm}$ for $0.25 \mathrm{~h}$. With the resulting powders from the milling, cylindrical samples of $20 \mathrm{~mm}$ in diameter by $3 \mathrm{~mm}$ in thickness were manufactured at a pressure of $185 \mathrm{MPa}$, with the help of a uniaxial press (Montequipo, Tlalnepantla de Baz, Mexico, LAB-30-T). Then, the pressed samples were sintered in an electric furnace (Carbolite, Sheffield, UK, RHF17/3E) at $581{ }^{\circ} \mathrm{C}$ and $601{ }^{\circ} \mathrm{C}$ for $1 \mathrm{~h}$ at atmospheric pressure. The heating rate was $8{ }^{\circ} \mathrm{C} / \mathrm{min}$, after the sintering time was reached, the furnace was turned off with the samples inside for their gradual cooling. The density of the samples was determined by the Archimedes method. The microstructure of the sintered samples was analyzed using scanning electron microscopy (JEOL, Akishima-shi, Japan, 6300). The SEM was equipped with an X-ray dispersive energy analyzer (Hitachi, Tokyo, Japan, SU9000 UHR FE-SEM). The mechanical properties of the obtained specimens were evaluated by microhardness using a Vickers microdurometer (Wilson Instruments, Campbellford, ON, Canada, S400); the elastic modulus was determined by the ultrasound method, using an ultrasonic sensor (GrindoSonic, Leuven, Belgium, A-360). The flexural strength at 3 points was determined in a universal testing machine (Instron, Norfolk County, MA, USA). Finally, the surface fractures were analyzed using a stereoscope (Olympus, Tokyo, Japan, SZ61). The values reported for all measurements are the average of the measurements made on 5 different samples for each system studied.

\section{Results and Discussion}

\subsection{Morphological Analysis of Powders}

Figure 1 shows pictures of the different study samples resulting from the grinding stage. In Figure 1a which corresponds to the control sample, an agglomeration of a large number of particles can be observed. For the case where WC is added (Figure 1b,c), although agglomerates formation is observed they are smaller, which indicates that somehow the presence of WC helps to prevent them from forming. This is perhaps because the WC affects the electrical properties on the surface of the aluminum, which causes the electrostatic forces to decrease in this area, thus avoiding the formation of large agglomerates, as has been suggested in the literature [21]. In Figure $1 b, c$, the particles with a lighter coloring belong to the WC and are easily distinguishable by the density difference of both components WC and Al. Likewise, samples with mullite (Figure 1d,e) show the behavior described for WC, although mullite seems to form larger agglomerates than those formed by the WC reinforcing, as it is difficult to distinguish mullite from aluminum because their densities are closer. In general, all the images show that the particles acquired the shape of flakes due to the type of grinding carried out and the strong ductility of the aluminum, which seems to have been laminated during the mechanical action of grinding. 

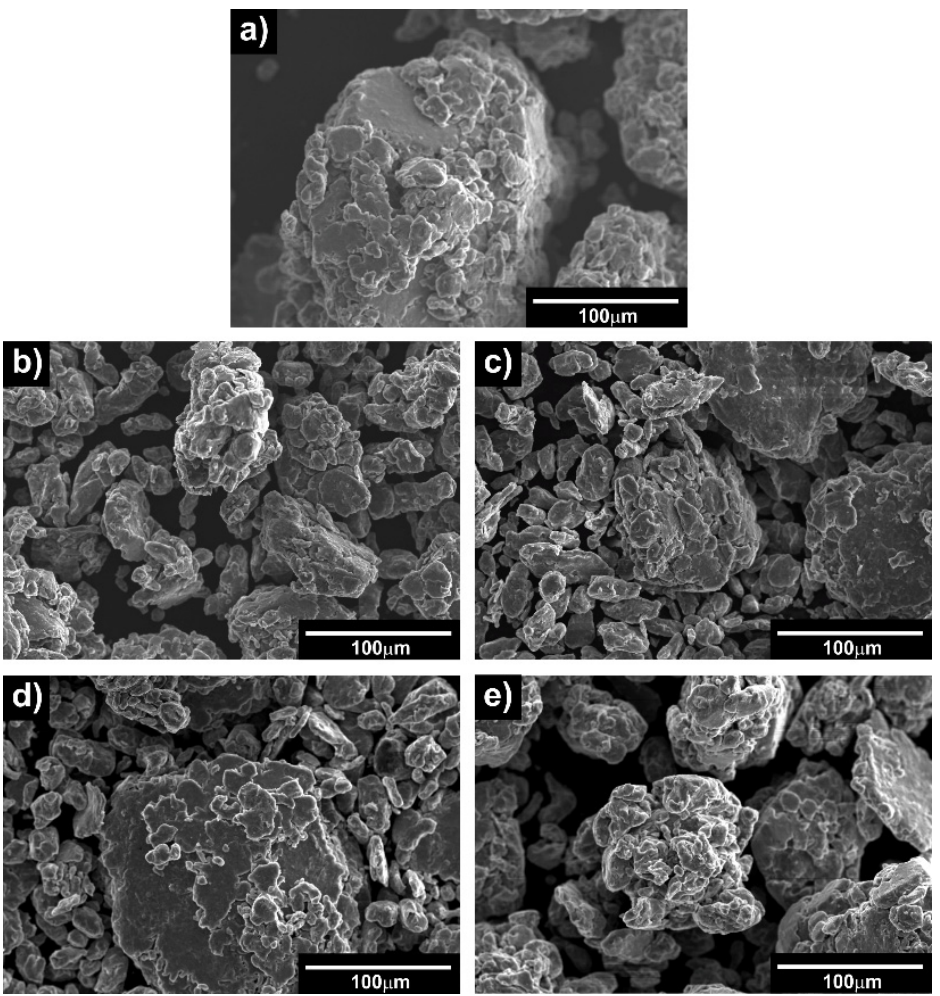

Figure 1. Micrograph of the powders after the grinding stage for the studied compositions: (a) 100 vol.\% Al, (b) $\mathrm{Al} / 0.5$ vol.\% WC, (c) $\mathrm{Al} / 1.0$ vol.\% WC, (d) $\mathrm{Al} / 0.5$ vol.\% mullite and (e) $\mathrm{Al} / 1$ vol. $\%$ mullite.

\subsection{Size Distribution of Powders}

Figure 2 shows the results of the particle size distribution performed on the 5 samples obtained after the milling stage. In this figure, it is observed that approximately $50 \%$ of the powders in all the samples have sizes smaller than $50 \mu \mathrm{m}$. However, during grinding, powders were obtained with varying sizes according to the composition of the samples. For the samples with additions of WC (Figure 2a), it can be seen that when a greater amount of reinforcement is added ( $1 \mathrm{vol} . \% \mathrm{WC}$ ), the particle size decreases (average of $48 \mu \mathrm{m}$ ), but it does not have a uniform distribution, while the addition of $0.5 \mathrm{vol} . \% \mathrm{WC}$ has a better size distribution, where the average particle size is $101 \mu \mathrm{m}$. Pure aluminum presented very large particle sizes, with an average of $126 \mu \mathrm{m}$, formed by agglomerates. In the case of the sample with mullite additions (Figure $2 b$ ), the size distribution is more homogeneous. In this case, the average particle size was $41 \mu \mathrm{m}$ for the sample with $0.5 \mathrm{vol} . \%$ mullite and $89 \mu \mathrm{m}$ for the sample with 1 vol. $\%$ mullite.

\subsection{Density}

Figure 3 shows the results of the measurements of the relative density on the samples evaluated through the Archimedes' principle. In this figure, it can be noted that the samples that best densify are those that contain mullite, as those samples with 1 vol.\% mullite have a better densification. With regard to the samples with WC, the densification of the samples is not significant, although the samples with $1 \mathrm{vol} . \%$ WC densifies more than that which contains 0.5 vol. $\%$ WC. With respect to the $100 \% \mathrm{Al}$ sample, the relative density reached by this is greater, while in the case of samples with WC, the density of these samples was lower than that of pure aluminum. On the other hand, the sintering temperature does not have an important effect on the densification of the samples, since in all cases similar densities are obtained regardless of the sintering temperature. 

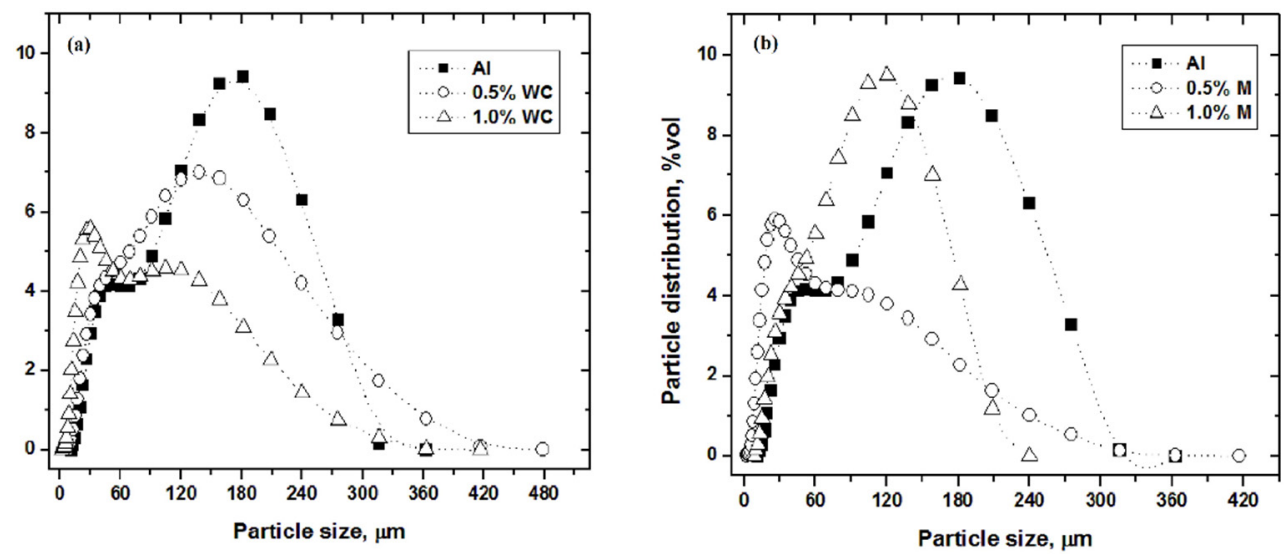

Figure 2. Distribution of particle sizes in powder samples after the grinding stage. (a) System with additions of WC, (b) System with additions of mullite.

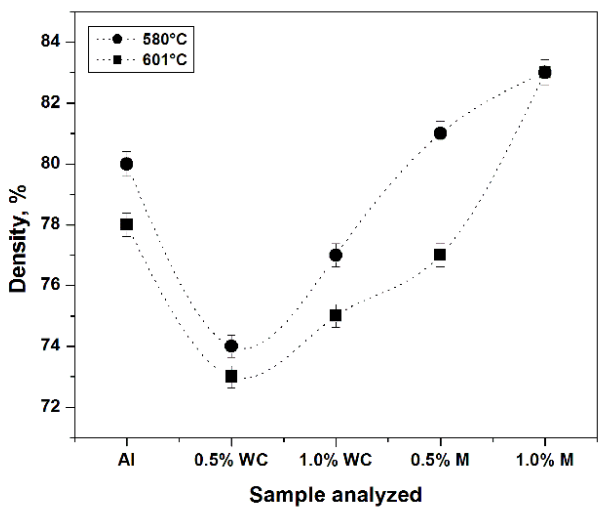

Figure 3. Results of the relative density reached by the samples with different compositions and sintered at different temperatures.

As can be seen in these results, very low densification values were achieved, it is well known that densification of powdered materials is a process of pore elimination whereby the porosity of these sintered alloys decreases with the increase of the time and correct sintering temperature. In this sense, the sintering conditions, mainly the times, were probably insufficient to achieve a better densification of the materials. Another factor to consider is the compaction pressure, where it is surely necessary to increase this pressure in order to achieve higher green densities. Finally, the better densification in the samples with mullite compared to those containing WC, is due to the difference in densities between these ceramics and $\mathrm{Al}$, this gap being greater between $\mathrm{Al}$ and $\mathrm{WC}$ than between $\mathrm{Al}$ and mullite.

\subsection{Microstructure}

Figure 4 shows the microstructures of the samples sintered at $601{ }^{\circ} \mathrm{C}$ for $1 \mathrm{~h}$. In all samples, very homogeneous microstructures in terms of shape and grain size can be observed. In the sample with WC contents, the presence of large pores is evident, which helps to explain the lower density reached by these samples. The smallest clear points present at inter and intragranular zones correspond to the reinforcing material added in each sample. This is verified with the EDX analyses performed on these points and shown in Figure 5 for the sample with WC and mullite, respectively, observing in Figure $5 \mathrm{a}$ the presence of the $\mathrm{W}$ as part of the $\mathrm{WC}$, and $\mathrm{Si}$ in Figure $5 \mathrm{~b}$ as a component of the mullite. 

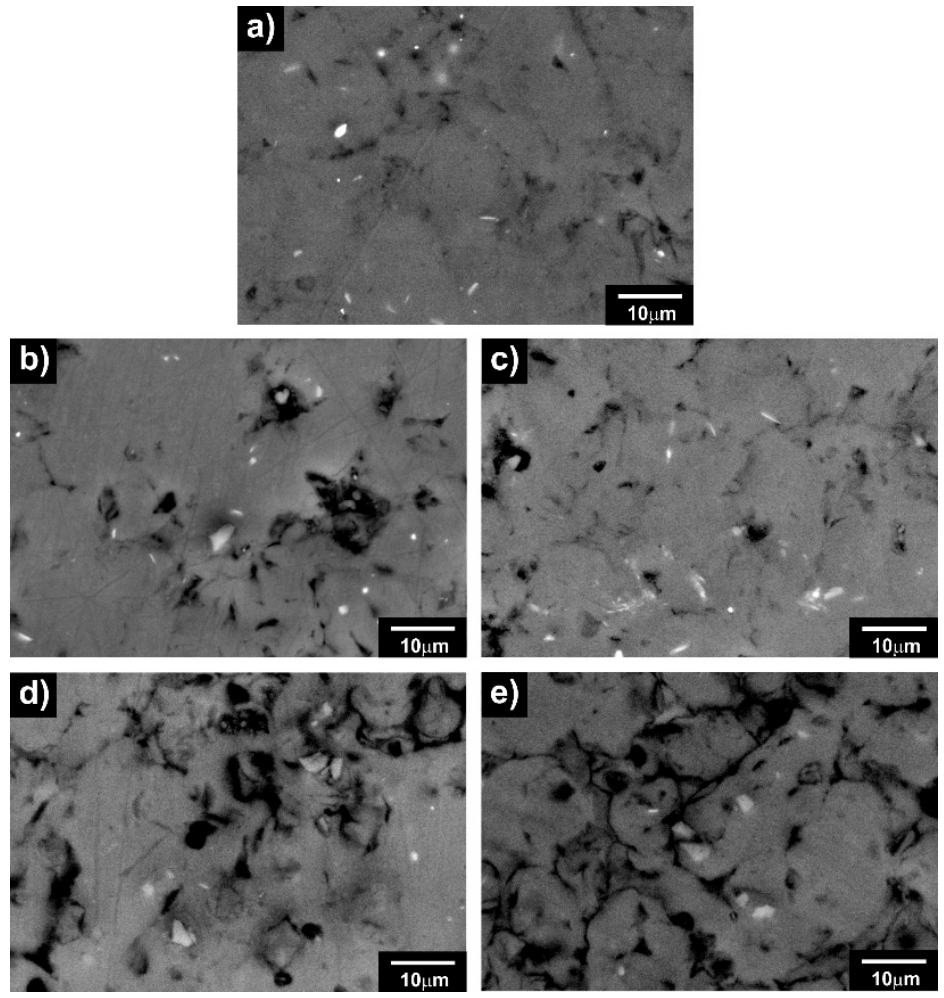

Figure 4. Microstructures of the samples sintered at $601{ }^{\circ} \mathrm{C}$, during $1 \mathrm{~h}$. (a) Pure aluminum, (b) Al-0.5 vol.\% WC, (c) Al-1 vol.\% WC, (d) Al-0.5 vol.\% Mullite and (e) Al-1 vol.\% mullite.
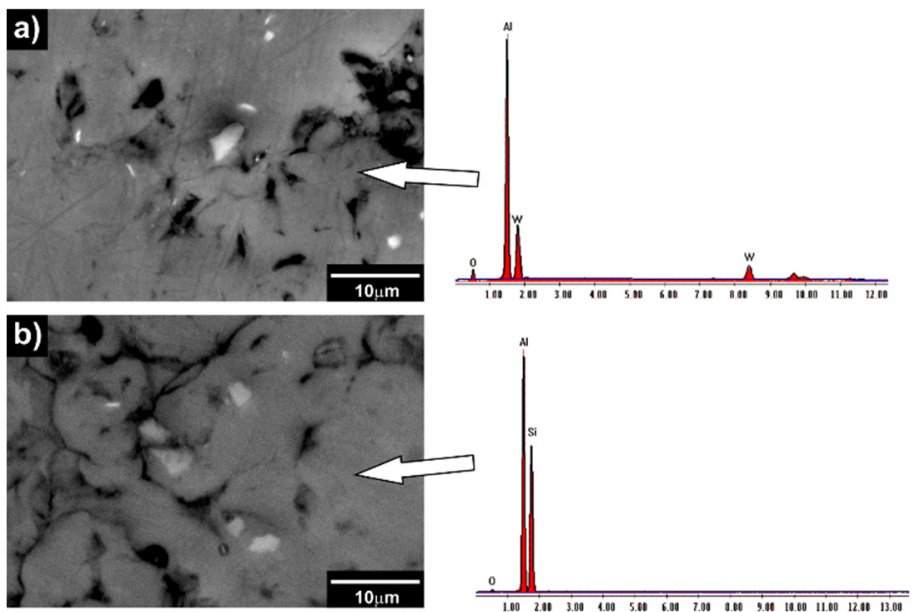

Figure 5. EDX made in samples sintered at $600^{\circ} \mathrm{C}$ for $1 \mathrm{~h}$, (a) composite of the matrix Al- 0.5 vol. $\%$ WC and (b) composite of the matrix Al-0.5 vol. $\%$ mullite.

\subsection{Mechanical Properties}

\subsubsection{Microhardness}

Figure 6 shows the results of the microhardness measurements made in the study samples. In this figure it is observed, as expected, that when adding ceramic particles of greater hardness than aluminum, this property will increase, being that the increase in hardness is greater for the sample with WC. Likewise, the increase in the amount of reinforcing material manifests itself as an increase in the hardness of the material. Again, it is observed that the sintering temperature does not have an important effect on the final hardness of the samples. 


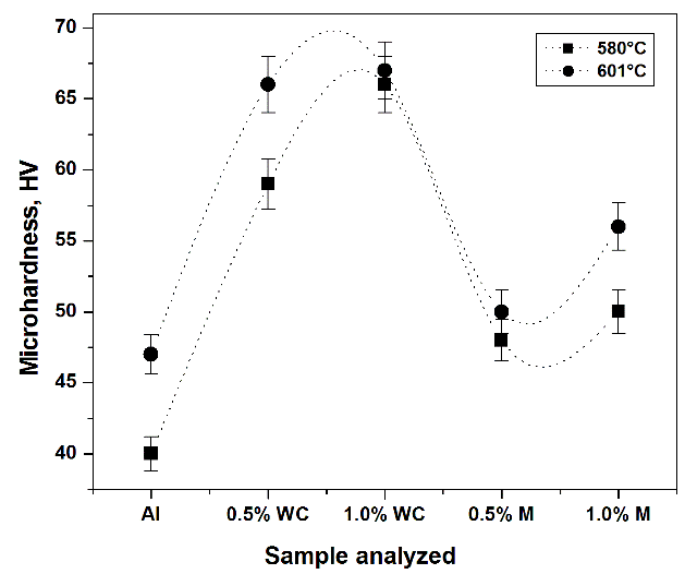

Figure 6. Results of the microhardness evaluated in the samples with different compositions and sintered at different temperatures.

\subsubsection{Elastic Modulus}

Figure 7 shows the elastic modulus measured in the study samples. The WC and mullite ceramic materials have a greater elastic modulus than aluminum, this condition is reflected in Figure 7, where the samples with additions of WC and mullite reached a final elastic modulus greater than those of pure aluminum. The elastic modulus of the samples with WC is greater because the elastic modulus of the WC is greater than that of the mullite. The behavior of the curves is similar, observing that the temperature does not significantly affect the final value of the elastic modulus.

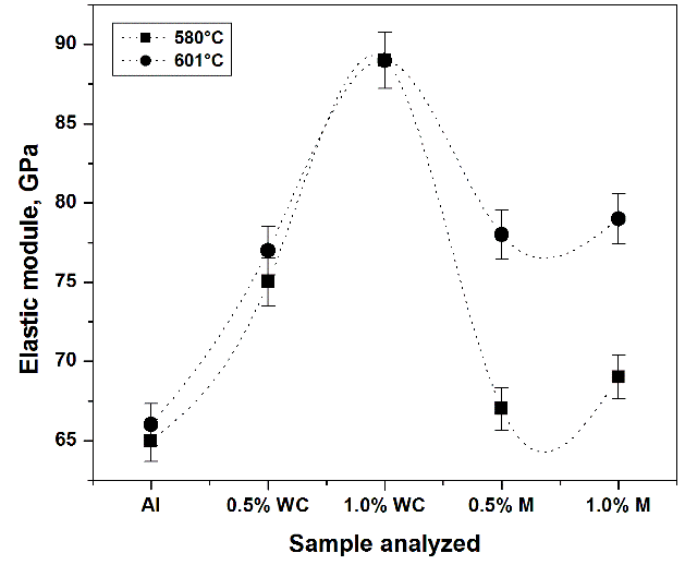

Figure 7. Results of the elastic modulus evaluated in the samples with different compositions and sintered at different temperatures.

\subsubsection{Bending Strength}

Figure 8 shows the results of bending resistance measurements. In this figure, it is appreciated that when adding a ceramic compound of greater hardness and lower ductility than the aluminum matrix, there is a decrease in the mechanical strength of the composite obtained, mainly in the sample with WC due to the strong fragile nature of this compound. For the case of mullite additions, likewise, there is a loss of strength in the material. However, what is sought when adding ceramic materials of great hardness compared with that of a soft and ductile metal such as aluminum is to increase the hardness and stiffness of this metal beyond its mechanical strength. 


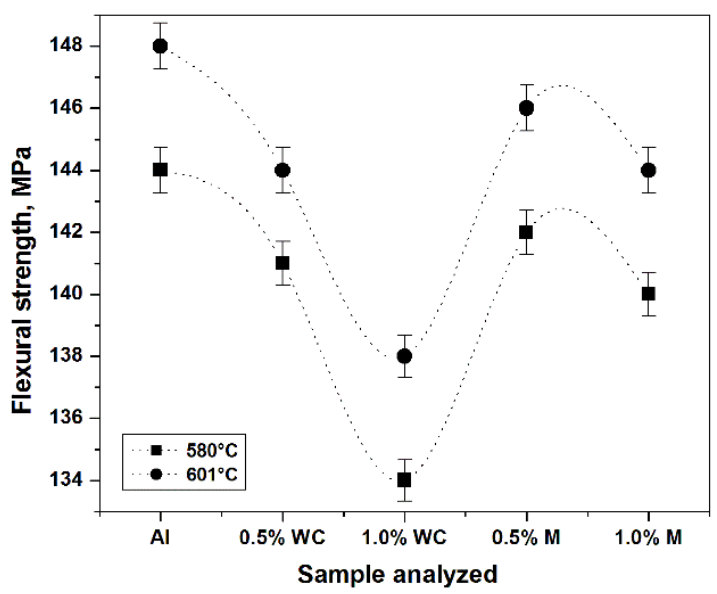

Figure 8. Results of the flexural strength measurements of the samples with different compositions and sintered at different temperatures.

\subsubsection{Fracture Surfaces}

Figure 9 shows images of the fracture surface of samples without reinforcement and with 1 vol.\% WC or mullite used as reinforcing materials. By means of these photographs, it can be observed that in all samples the fracture had a fragile behavior, since there is a complete detachment of grains. This is caused by the processing route that does not allow a solid conforming, since according to the results of evaluated densities, the samples have a certain porosity, as the presence of these pores is where the cracks have their origin.
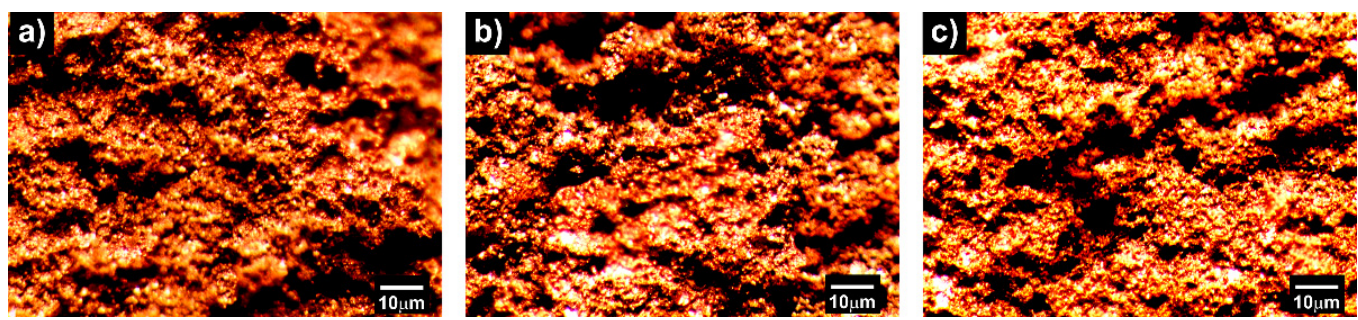

Figure 9. Images taken with a stereographic microscope from the fracture surface area of the composite (a) Pure aluminum, (b) Al-1 vol.\% WC and (c) Al-1 vol.\% mullite.

From the results of the mechanical properties evaluated in the composites obtained here, we have that the reinforcement of ductile metals by means of ceramic particles, materials that are hard and brittle in nature, coupled with powder metallurgy processing, can only be reflected in increases in the hardness and elastic modulus of the metal, since the microstructures present only the distribution of the two phases in a homogeneous way, without the formation of solid solutions. Therefore, it is not feasible to achieve increases in the strength and ductility of the resulting materials through this type of process and reinforcement, a situation that has been well documented by other researchers [22].

\section{Conclusions}

- Aluminum-based composites can be effectively hardened by dispersing mullite particles and tungsten carbide, through powder metallurgy techniques that involve the combination of mechanical grinding, cold compaction, and pressureless sintering. The results showed that reinforced ceramics provided aluminum increments in hardness and stiffness properties.

- The reinforcement of ductile metals by means of ceramic particles, materials that are hard and brittle in nature, coupled with powder metallurgy processing can only be reflected in increases in the hardness and elastic modulus of the metal, since the microstructures present only the distribution of the two phases in a homogeneous way, without the formation of solid solutions. Therefore, it is not feasible to achieve 
increases in the strength and ductility of the resulting materials through this type of process and reinforcement

- Microstructure observations indicate that mullite particles are located at intragranular and transgranular positions of the aluminum matrix, while tungsten carbide particles were found mostly at intragranular areas of the matrix.

- This processing methodology, with favorable results in terms of increasing the mechanical properties of aluminum, can be a simple and inexpensive processing alternative, which makes it attractive to scale the process at the industrial level.

\begin{abstract}
Author Contributions: Conceptualization, J.A.C.-R., A.P.D.-M. and E.R.-R.; methodology, J.A.C.-R. and A.P.D.-M.; validation, J.A.R.-G., E.N.A.-M. and W.J.P.-R.; formal analysis, E.R.-R. and C.A.C.-A.; investigation, J.A.C.-R. and A.P.D.-M.; resources, E.R.-R.; data curation, J.A.R.-G., E.N.A.-M. and W.J.P.-R.; writing—original draft preparation, J.A.C.-R. and A.P.D.-M.; writing-review and editing, E.R.-R. and C.A.C.-A.; visualization, E.R.-R.; supervision, E.R.-R.; project administration, E.R.-R.; All authors have read and agreed to the published version of the manuscript.
\end{abstract}

Funding: This research received no external funding.

Conflicts of Interest: The authors declare no conflict of interest.

\title{
References
}

1. Da Costa, E.; Velasco López, C.; Torralba Castelló, J. Materiales compuestos de matriz metálica. I parte. Tipos, propiedades, aplicaciones. Rev. Metal. 2000, 36, 179-192. [CrossRef]

2. Lindroos, V.; Talvitie, M. Recent advances in metal matrix composites. J. Mater. Process. Technol. 1995, 53, 273-284. [CrossRef]

3. Prasad, S.; Asthana, R. Aluminum Metal-Matrix Composites for Automotive Applications: Tribological Considerations. Tribol. Lett. 2004, 17, 445-453. [CrossRef]

4. Hooker, J.; Doorbar, P. Metal matrix composites for aeroengines. In Metal and Ceramic Matrix; Cantor, B., Stone, I., Dunne, F., Eds.; Institute of Physics Publishing: Philadelphia, PA, USA, 2004; pp. 12-26.

5. Torralba, J.; da Costa, C.; Velasco, F.J. P/M aluminum matrix composites: An overview. J. Mater. Process. Technol. 2003, 133, 203-206. [CrossRef]

6. Kumar, G.B.V.; Rao, C.S.P.; Selvaraj, N. Mechanical and Tribological Behavior of Particulate Reinforced Aluminum Metal Matrix Composites-A review. J. Miner. Mater. Charact. Eng. 2011, 10, 59-91. [CrossRef]

7. Bodukuri, A.K.; Eswaraiah, K.; Rajendar, K.; Sampath, V. Fabrication of Al-SiC-B4C metal matrix composite by powder metallurgy technique and evaluating mechanical properties. Perspect. Sci. 2016, 8, 428-431. [CrossRef]

8. Verma, J.; Kumar, A.; Chandrakar, R.; Kumar, R. Processing of 5083 Aluminum Alloy Reinforced with Alumina through Microwave Sintering. J. Miner. Mater. Charact. Eng. 2012, 11, 1126-1131. [CrossRef]

9. Tyagi, R. Synthesis and tribological characterization of in situ cast Al-TiC composites. Wear 2005, 259, 569-576. [CrossRef]

10. Gomes, L.A.C.M.; Travessa, D.N.; González-Carrasco, J.L.; Lieblich, M.; Cardoso, K.R. Production of MA956 Alloy Reinforced Aluminum Matrix Composites by Mechanical Alloying. Mater. Res. 2015, 18, 48-54. [CrossRef]

11. Cuevas, J.C.; Barona, W.; Sanchez, H.; Castro, I. Reforzamiento de la aleación de aluminio 6061 con carburos dobles de Fe-Cr obtenidos por aleación mecánica. Sci. Tech. 2007, 1, 119-124. [CrossRef]

12. Daoud, A.; Abou-Elkhair, M.T.; Rohatgi, P. Wear and friction behavior of near eutectic Al-Si+ZrO ${ }_{2}$ or WC Particle Composites. Compo. Sci. Tech. 2004, 64, 1029-1040. [CrossRef]

13. Nestler, D.; Siebeck, S.; Podlesak, H.; Wagner, S.; Hockauf, M.; Bernhard, W. Powder Metallurgy of Particle-Reinforced Aluminium Matrix Composites (AMC) by Means of High-Energy Ball Milling. Integ. Syst. Des. Tech. 2010, 93-107. [CrossRef]

14. Wu, Y.; Lavemia, E.J. Advancements in synthesis and processes. In Proceedings of the Advancements in Synthesis and Processes, Toronto, ON, Canada, 20-22 October 1992. Society for Advancement of Material and Process Engineering M692.

15. Tiwari, R.; Herman, H.; Sampath, S.; Gudmundsson, B. Plasma spray consolidation of high temperature composites. Mater. Sci. Eng. A 1991, 144, 127-131. [CrossRef]

16. Kim, S.W.; Lee, U.J.; Han, S.W.; Kim, D.K.; Ogi, K. Heat treatment and wear characteristics of Al/SiCp composites fabricated by duplex process. Compos. Part B Eng. 2003, 34, 737-745. [CrossRef]

17. Prashantha Kumar, H.G.; Anthony Xavior, M.A. Graphene Reinforced Metal Matrix Composite (GRMMC): A Review. Proc. Eng. 2014, 97, 1033-1040. [CrossRef]

18. Venkatesan, S.; Xavior, M.A. Tensile behavior of aluminum alloy (AA7050) metal matrix composite reinforced with graphene fabricated by stir and squeeze cast processes. Sci. Technol. Mater. 2018, 30, 74-85. [CrossRef]

19. Prashantha Kumar, H.G.; Anthony Xavior, M.A. Encapsulation and Microwave Hybrid Processing of Al 6061-Graphene-SiC Composites. Mater. Manuf. Process. 2017, 33, 19-25. [CrossRef]

20. Singh, L.; Kumar, S.; Raj, S.; Badhani, P. Aluminium Metal Matrix Composites: Manufacturing and Applications. IOP Conf. Ser. Mater. Sci. Eng. 2021, 1149, 012025. [CrossRef] 
21. Trunec, M.; Maca, K. Advanced Ceramic Processes. In Advanced Ceramics for Dentistry, 1st ed.; Shen, J.Z., Kosmač, T., Eds.; Elsevier Science: Amsterdam, The Netherlands, 2014; pp. 123-150.

22. Clyne, T.W. Metallic Composite Materials. In Physical Metallurgy, 4th ed.; Cahn, R.W., Haasen, P., Eds.; Elsevier Science: Amsterdam, The Netherlands, 1996; pp. 2567-2625. 